\title{
SISTEM PENENTUAN PENERIMA RASKIN MENGGUNAKAN METODE FUZZY ANALITICAL HIERARCHY PROCESS
}

\author{
Deddy Kusbianto Purwokoaji ${ }^{1}$, Meyti Eka Apriani², Rizky Purnamasari ${ }^{3}$
}

1,2,3 Program Studi Teknik Informatika, Jurusan Teknologi Informasi, Politeknik Negeri Malang

${ }^{1}$ deddy_kusbianto@polinema.ac.id, ${ }^{2}$ meytieka@polinema.ac.id, ${ }^{3}$ riskypurnama39@gmail.com

\begin{abstract}
Abstrak
Raskin merupakan Program beras miskin yang dimulai pada bulan januari 2002 merupakan program lanjutan dari program Operasi Pasar Khusus (OPK) yang dirancang pemerintah dan dilaksanakan oleh Bulog 1998. Program RASKIN yang diterapkan di Desa Sukorame Kecamatan Binangun Kabupaten Blitar, dalam pendataannya dilakukan melalui kader-kader dari beberapa Rukun Tetangga (RT). Proses pendataan yang dilakukan oleh kader masih belum menyeluruh dan bersifat subjektif Sehingga dibutuhkan sistem seleksi penerima RASKIN dengan menggunakan Sistem Pendukung Keputusan (SPK). Sistem Pendukung Keputusan merupakan bagian dari sistem informasi berbasis komputer yang dapat mengatasi masalah ini. Sistem ini berguna untuk memudahkan pengambil keputusan yang terkait dengan masalah seleksi penerima beras untuk keluarga miskin, sehingga menghasilkan keluarga yang paling layak menerima Raskin. Pembuatan Sistem Pendukung Keputusan (SPK) ini bertujuan sebagai alat bantu bagi kelurahan untuk menentukan calon penerima RASKIN secara tepat, dengan menggunakan metode Fuzzy Analitical Hierarchy Process.
\end{abstract}

Kata kunci : sistem sendukukung keputusan, raskin, fuzzy analitical hierarchy process

\section{PENDAHULUAN}

Program beras miskin yang dimulai pada bulan januari 2002 merupakan program lanjutan dari program Operasi Pasar Khusus (OPK) yang dirancang pemerintah dan dilaksanakan oleh Bulog 1998. Raskin diperluas fungsinya tidak lagi menjadi program darurat (social safety net) melainkan sebagai bagian dari program perlindungan sosial masyarakat. Melalui sebuah kajian ilmiah penamaan RASKIN menjadi nama program diharapkan akan menjadi lebih tepat sasaran dan mencapai tujuan RASKIN Rafifah ( 2018)

Program RASKIN yang diterapkan di Desa Sukorame Kecamatan Binangun Kabupaten Blitar, dalam pendataannya dilakukan melalui kader-kader dari beberapa Rukun Tetangga (RT). Proses pendataan yang dilakukan oleh kader masih belum menyeluruh dan bersifat subjektif, sehingga masih banyak warga yang seharusnya mandapatkan RASKIN masih belum mendapatkan.

Pada kasus sebelumnya telah dilakukan penelitian tentang sistem yang dapat melakukan pencarian penerima bantuan beras miskin yangg berjudul "Penerapan Metode Analytical Hierarachy Proces Untuk Sistem Pendukung Keputusan Penerima Raskin" Didalam jurnal tersebut bagian Kesimpulan dan saran menganjurkan menggunakan metodemetode Sistem Pendukung Keputusan yang lain untuk membandingkan hasil keakuratan hasil keputusan tersebut

\section{LANDASAN TEORI}

\subsection{Sistem Pendukung Keputusan}

Sistem pendukung keputusan (SPK) biasanya dibangun untuk mendukung soluasi atas suatu masalahatau mengevaluasi suatu peluang.Sistem pendukungkeputusan yang seperti itu disebut aplikasi Sistem Pendukung Keputusan. Aplikasi ini menggunakan CBIS (Computer Based Information System) yang fleksibel, interaktif dan dapat diadaptasi yang dikembangkan untuk mendukung solusi atas masalah manajemen spesifik yang tidak terstruktur, (Kusrini, 2007). Menurut Turban, dkk (2005, h.321) Sistem Pendukung Keputusan (SPK) adalah suatu sistem informasi berbasis computer mengkombinasikan model dan data untuk menyediakan dukungan kepada pengambil keputusan dalam memecahkan masalah semi terstruktur atau masalah ketergantungan yang melibatkan user secara mendalam.Sistem Pendukung Keputusan merupakan sebuah sistem yang menyediakan kemampuan untuk penyelesaian masalah dan komunikasi untuk permasalahan yang bersifat semi terstruktur (Raymond McLeod, Jr. (1998)

\subsection{Raskin}

Penyaluran RASKIN (Beras untuk Rumah Tangga Miskin) sudah dimulai sejak 1998. Krisis moneter tahun 1998 merupakan awal pelaksanaan RASKIN yang bertujuan untuk memperkuat ketahanan pangan rumah tangga terutama rumah tangga miskin. Pada 
awalnya disebut program Operasi Pasar Khusus (OPK), kemudian diubah menjadi RASKIN mulai tahun 2002, RASKIN diperluas fungsinya tidak lagi menjadi program darurat (social safety net) melainkan sebagai bagian dari program perlindungan sosial masyarakat. Melalui sebuah kajian ilmiah, penamaan RASKIN menjadi nama program diharapkan akan menjadi lebih tepat sasaran dan mencapai tujuan RASKIN. Penentuan kriteria penerima manfaat RASKIN seringkali menjadi persoalan yang rumit. Dinamika data kemiskinan memerlukan adanya kebijakan lokal melalui musyawarah Desa/Kelurahan. Musyawarah ini menjadi kekuatan utama program untuk memberikan keadilan bagi sesama rumah tangga miskin. Sampai dengan tahun 2006, data penerima manfaat RASKIN masih menggunakan data dari BKKBN yaitu data keluarga prasejahtera alasan ekonomi dan keluarga sejahtera I alasan ekonomi. Belum seluruh KK Miskin dapat dijangkau oleh RASKIN. Hal inilah yang menjadikan RASKIN sering dianggap tidak tepat sasaran, karena rumah tangga sasaran berbagi dengan KK Miskin lain yang belum terdaftar sebagai sasaran.

\subsection{Fuzzy Analytical Hierarchy Process}

Fuzzy Analytical Hierarchy Process (FAHP) merupakan metode analitik yang dikembangkan dari metode AHP dengan menggunakan pendekatan fuzzy. Metode ini dikembangkan untuk memperbaiki kelemahan yang ada pada metode AHP, yaitu untuk mengatasi ketidakmampuan metode AHP dalam memberikan penilaian yang presisi pada matriks perbandingan berpasangan, Turan H., (2016). Perbedaan metode ini dengan metode AHP terletak pada implementasi penilaian dalam matriks perbandingan berpasangan antar kriteria, di mana pada F-AHP nilai setiap kriteria diwakili oleh tiga variabel (a, b, c) atau (1, m, u) yang disebut Triangular Fuzzy Number (TFN).

Setiap fungsi keanggotaan didefinisikan dalam 3 parameter yakni, $1, \mathrm{~m}$, dan $\mathrm{u}$, dimana 1 adalah nilai kemungkinan terendah, $\mathrm{m}$ adalah nilai kemungkinan tengah dan $\mathrm{u}$ adalah nilai kemungkinan teratas pada interval putusan pengambil keputusan. Nilai 1, m, dan $\mathrm{u}$ dapat juga ditentukan oleh pengambil keputusan itu sendiri. Tulisan ini mengajukan tiga parameter bilangan fuzzy untuk merepresentasikan skala Saaty (1-9) sesuai dengan tingkat kepentingannya, yakni: Gani, A. N., \& Assarudeen, S. M. (2012)

Triangular Fuzzy Number (TFN) dapat menunjukkan kesubjektifan perbandingan berpasangan atau dapat menunjukkan derajat yang pasti dari kekaburan (ketidakpastian). Dalam hal ini variabel linguistik dapat digunakan oleh pengambil keputusan untuk merepresentasikan kekaburan data seandainya ada ketidaknyamanan dengan TFN. TFN dan variabel linguistiknya sesuai dengan skala Saaty. Langkah - langkah penyelesaiaan metode FuzzyAnalytical Hierarchy Process, yaitu: a. Membuat struktur hirarki masalah yang akan diselesaikan dan menentukan perbandingan matriks berpasangan antar kriteria dengan skala TFN

b. Menentukan nilai sintesis fuzzy (Si) prioritas dengan rumus.

$$
\mathrm{Si}=\sum_{j=1}^{m} M_{g i}^{j} \quad \text { х } \frac{1}{\left[\sum_{i=1}^{m} \sum_{j=1}^{m} M_{g i}^{j}\right.}
$$

Dimana :

$\mathrm{Si}=$ nilai sintesis fuzzy

$\sum_{j=1}^{m}=$ nilai sel pada kolom dimulai dari kolom 1 di setiap baris matriks.

$i=$ baris

$j=$ kolom

Untuk memperoleh $\sum_{j=1}^{m} M_{g i}^{j}$ yaitu dengan menggunakan penjumlahan fuzzy dari nilai $m$ pada sebuah matrik seperti dibawah ini ,

$$
\begin{gathered}
\sum_{j=1}^{m} M_{g i}^{j}=\left(\sum_{j=1}^{m} l j, \sum_{j=1}^{m} m j,\right. \\
\sum_{j=1}^{m} u j
\end{gathered}
$$

menambahkan operasi fuzzy dari $M_{g i}^{j}(\mathrm{j}=$ $1,2, \ldots . ., \mathrm{m})$, sehingga

$$
\frac{1}{\left[\sum_{i=1}^{n} \sum_{j=1}^{m} M_{g i}^{j}\right]}=\left(\frac{1}{\sum_{i=1}^{n} u i, \sum_{i=1}^{n} m i, \sum_{i=1}^{n} l i}\right)
$$

(3)

Sehingga persamaan(2) menjadi

$$
\begin{aligned}
& \mathrm{Si}=\left(\sum_{j=1}^{m} l j ; \sum_{j=1}^{m} m j ; \sum_{j=1}^{m} u j ;\right) \otimes \\
& \left.\frac{1}{\left[\sum_{i=1}^{n} u i\right]} ; \frac{1}{\left[\sum_{i=1}^{n} m i\right]} ; \frac{1}{\left[\sum_{i=1}^{n} l i\right]}\right)
\end{aligned}
$$

Normalisasi vektor bobot dilakukan untuk mempermudah interpretasi. Normalisasi akan dilakukan agar nilai dalam bobot vektor dipebolehkan menjadi analog bobot dan terdiri dari bilangan yang non-fuzzy.

\section{METODELOGI PENELITIAN}

Metode yang digunakan dalam pembuatan aplikasi Sistem Pendukung Keputusan Penentuan Penerima RASKIN Menggunakan Metode Fuzzy Analitical Hierarchy Proces model SDLC (System Development Life Cycle) dengan metode Waterfall. Gambaran singkat metodologi penelitian ini dapat dijelaskan sebagai berikut :

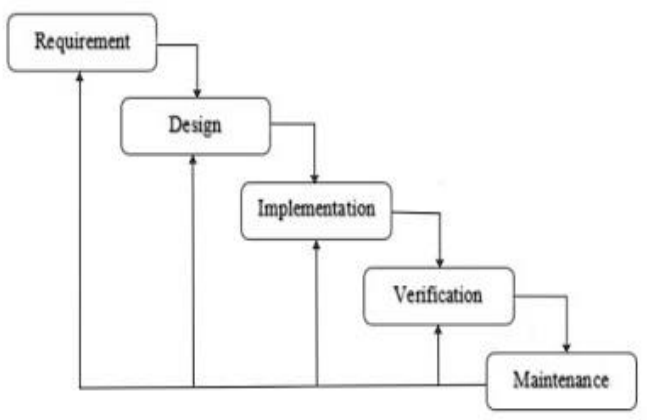

Gambar 1. Tahapan Pengembangan Sistem 


\subsection{Pengumpulan Data}

Pada tahap ini dilakukan wawancara dan diskusi akan kebutuhan data untuk merancang Sistem Pendukung Keputusan Penentu Penerima Raskin Menggunakan Metode Fuzzy Analitial Hierarchy Process Di Desa Sukorame, yang dilakukan dengan wawancara data narasumber dari dinas yang terkait di desa Sukorame yang digunakan sebagai landasan teori dalam penulisan laporan ini. Data RASKIN dan data setiap kepala keluarga diperoleh dari sekretaris desa berupa data excel seperti pada gambar dibawah ini :

\begin{tabular}{|c|c|c|c|c|c|c|}
\hline No & NIK & $\begin{array}{c}\text { Nama } \\
\text { Lengkap }\end{array}$ & Pendidikan & Pekerjaan & $\begin{array}{c}\text { Penghasila } \\
\text { n }\end{array}$ & $\begin{array}{c}\text { Angg } \\
\text { ota } \\
\text { Kelua } \\
\text { rga }\end{array}$ \\
\hline 1 & $\begin{array}{l}35051615079100 \\
03\end{array}$ & $\begin{array}{l}\text { IMAM } \\
\text { MAHDI }\end{array}$ & $\begin{array}{l}\text { SLTA/SEDER } \\
\text { AJAT }\end{array}$ & WIRASWASTA & 1.000 .000 & 2 \\
\hline 2 & $\begin{array}{l}35051660053800 \\
01\end{array}$ & SUMINI & $\begin{array}{l}\text { SLTP/SEDER } \\
\text { AJAT }\end{array}$ & $\begin{array}{l}\text { PETANI/PEKEB } \\
\text { UN }\end{array}$ & 2.200 .000 & 4 \\
\hline 3 & $\begin{array}{l}35051610118300 \\
02\end{array}$ & MESENO & $\begin{array}{l}\text { TIDAK } \\
\text { TAMAT SD }\end{array}$ & $\begin{array}{l}\text { KARYAWAN } \\
\text { SWASTA }\end{array}$ & 700.000 & 2 \\
\hline 4 & $\begin{array}{l}35051656018900 \\
02\end{array}$ & $\begin{array}{l}\text { DEWI } \\
\text { SETIANI }\end{array}$ & $\begin{array}{l}\text { SLTP/SEDER } \\
\text { AJAT }\end{array}$ & $\begin{array}{l}\text { PETANI/PEKEB } \\
\text { UN }\end{array}$ & 900.000 & 4 \\
\hline 5 & $\begin{array}{l}35051604045200 \\
03\end{array}$ & $\begin{array}{l}\text { GUNAW } \\
\text { AN }\end{array}$ & $\begin{array}{l}\text { SLTP/SEDER } \\
\text { AJAT }\end{array}$ & $\begin{array}{l}\text { PETANI/PEKEB } \\
\text { UN }\end{array}$ & .100 .000 & 1 \\
\hline 6 & $\begin{array}{l}35051650107700 \\
06\end{array}$ & $\begin{array}{l}\text { MUTOMI } \\
\text { MAH }\end{array}$ & $\begin{array}{l}\text { TAMAT } \\
\text { SD/SEDERAJ } \\
\text { AT }\end{array}$ & $\begin{array}{l}\text { PETANI/PEKEB } \\
\text { UN }\end{array}$ & 900.000 & 5 \\
\hline 7 & $\begin{array}{l}35051661058700 \\
02\end{array}$ & ISMIATI & $\begin{array}{l}\text { TAMAT } \\
\text { SD/SEDERAJ } \\
\text { AT }\end{array}$ & $\begin{array}{l}\text { PETANI/PEKEB } \\
\text { UN| }\end{array}$ & .200 .000 & 5 \\
\hline 8 & $\begin{array}{l}35051607116700 \\
04\end{array}$ & TARI & $\begin{array}{l}\text { TAMAT } \\
\text { SD/SEDERAJ } \\
\text { AT }\end{array}$ & $\begin{array}{l}\text { PETANI/PEKEB } \\
\text { UN }\end{array}$ & 00.000 & 4 \\
\hline 9 & $\begin{array}{l}35051662084500 \\
01\end{array}$ & WARINI & $\begin{array}{l}\text { TAMAT } \\
\text { SD/SEDERAJ } \\
\text { AT }\end{array}$ & $\begin{array}{l}\text { PETANI/PEKEB } \\
\text { UN }\end{array}$ & 400.000 & 1 \\
\hline 10 & $\begin{array}{l}35051641073600 \\
64\end{array}$ & $\begin{array}{l}\text { BONIYE } \\
\text { M SIBO }\end{array}$ & $\begin{array}{l}\text { SLTP/SEDER } \\
\text { AJAT }\end{array}$ & $\begin{array}{l}\text { PETANI/PEKEB } \\
\text { UN }\end{array}$ & 2.900 .000 & 1 \\
\hline
\end{tabular}

Gambar 2. Data KK

\begin{tabular}{|c|c|l|c|c|c}
\hline NO & \multicolumn{1}{|c|}{ Desa } & Kepala kelurga & \multicolumn{1}{|c|}{ Alamat } & $\begin{array}{c}\text { Anggota } \\
\text { keluarga }\end{array}$ & Tahun \\
\hline 1 & SUKORAME & IMAM MAHDI & $\begin{array}{l}\text { DUSUN SUKOMULYO } \\
\text { RW 001 RT 003 }\end{array}$ & 2 & 2017 \\
\hline 2 & SUKORAME & $\begin{array}{l}\text { NYOTO } \\
\text { PRASETYO }\end{array}$ & $\begin{array}{l}\text { DUSUN SUKOMULY } \\
\text { RW 01 RT 003 }\end{array}$ & 4 & 2017 \\
\hline 3 & SUKORAME & MESENO & $\begin{array}{l}\text { DUSUN SUKOMULYO } \\
\text { RW 001 RT 004 }\end{array}$ & 2 & 2017 \\
\hline 4 & SUKORAME & $\begin{array}{l}\text { DAYID SETYO } \\
\text { SUDAR WOKO }\end{array}$ & $\begin{array}{l}\text { DUSUN SUKOMULYO } \\
\text { RW 001 RT 004 }\end{array}$ & 4 & 2017 \\
\hline 5 & SUKORAME & GUNAWAN & $\begin{array}{l}\text { DUSUN SUKOMULYO } \\
\text { RW 001 RT 004 }\end{array}$ & 1 & 2017 \\
\hline 6 & SUKORAME & SAKIM & $\begin{array}{l}\text { DUSUN SUKOMULY } \\
\text { RW 002 RT 002 }\end{array}$ & 5 & 2017 \\
\hline 7 & SUKORAME & SULIS SUSANTO & $\begin{array}{l}\text { DUSUN SUKOMULY } \\
\text { RW 002 RT 002 }\end{array}$ & 5 & 2017 \\
\hline 8 & SUKORAME & KUWAT & $\begin{array}{l}\text { DUSUN SUKOMULYO } \\
\text { RW 002RT 002 }\end{array}$ & 4 & 2017 \\
\hline 9 & SUKORAME & GIYAH & $\begin{array}{l}\text { DUSUN SUKOMULY } \\
\text { RW 002 RT 004 }\end{array}$ & 1 & 2017 \\
\hline 10 & SUKORAME & MESELAN & $\begin{array}{l}\text { DUSUN SUKOMULYO } \\
\text { RW 002RT 004 }\end{array}$ & 5 & 2017 \\
\hline
\end{tabular}

Gambar 3. Data Raskin 2017

\subsection{Pengolahan Data}

Setelah data terkumpul proses selanjutnya adalah melakukan perhitungan pembobotan dengan menggunakan Fuzzy Analitical Hierarchy Process dan perangkingan menggunakan SAW. Yang di mulai dari tahapan Penentuan kriteria, perbandingan berpasangan, Pembobotan AHP, menghitung skala prioritas $\mathrm{CI}$, tingkat kepentingan TFN, perhitungan $\mathrm{F}$ AHP, menghitung sintesis vektor, deffuzyfikasi kemudian setelah menghasilkan nilai bobot setiap kriteria selanjutnya dilakukan prosses perangkingan dengan cara mengalikan nilai kriteria dengan bobot setiap kriteria.

\section{PERANCANGAN}

\subsection{Gambaran Umum Sistem}

Sistem Pendukung Keputusan Penentuan Penerima RASKIN Menggunakan Metode Fuzzy Analitical Hierarchy Process Di Desa Sukorame merupakan sebuah sistem penentuan keputusan untuk mempermudah user dalam menentukan siapa yang berhap mendapatkan beras miskin berdasarkan kriteria. Sistem ini diperuntukkan untuk user yaitu kader - kader desa yang mengurusi data RASKIN. User dapat melakukan perangkingan berdasarkan kriteria - kriteria yang telah di tentukan dengan menggunakan metode Fuzzy Analitical Hierarchy Process.

\subsection{Usecase Diagram}

Usecase Diagram adalah rangkaian atau uraian kelompok yang saling terkait dan membentuk sistem secara teratur yang dilakukan atau diawasi oleh sebuah aktor. Dalam sistem ini terdapat dua aktor yaitu admin dan super admin. Usecase diagram untuk sistem yang akan dibuat dapat dilihat pada Gambar 4 Usecase Diagram

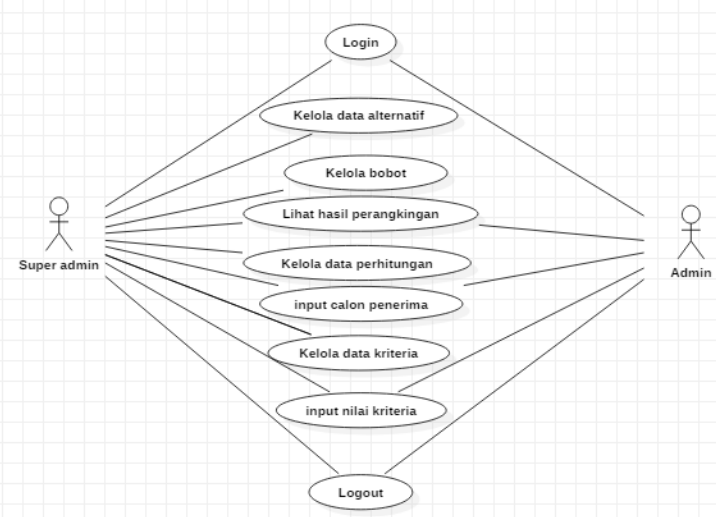

Gambar 4. Use Case Diagram

Pada sistem ini super admin dapat melakukan :
1) Login
2) Kelola data alternatif
3) Kelola bobot
4) Lihat hasil perangkingan
5) Kelola data perhitungan
6) Input calon penerima
7) Kelola data kriteria
8) Input nilai kriteria
9) Logout

Sistem dapat melakukan :
1) Login
2) Lihat hasil perangkingan
3) Input calon penerima
4) Input nilai kriteria
5) Logout 


\subsection{Flowchart}

Flowchart adalah suatu bagan yang mempresentasikan dengan simbol-simbol tertentu untuk menggambarkan urutan proses secara mendetail dan hubungan antara suatu proses dengan proses lainnya dalam suatu program. Pada flowchart terdapat bagan-bagan yang mempunyai arus yang menggambarkan langkah-langkah penyelesaian suatu masalah Flowchart merupakan cara penyajian dari suatu algoritma.Pada penelitian pengenalan nilai mata uang kertas utuk tunanetra ini menggunakan Flowchart diagram untuk menggambarkan urutan logis aplikasi secara jelas. Berikut flowchart metode Fuzzy analitical hierarchy Proccess dan flowchart SAW

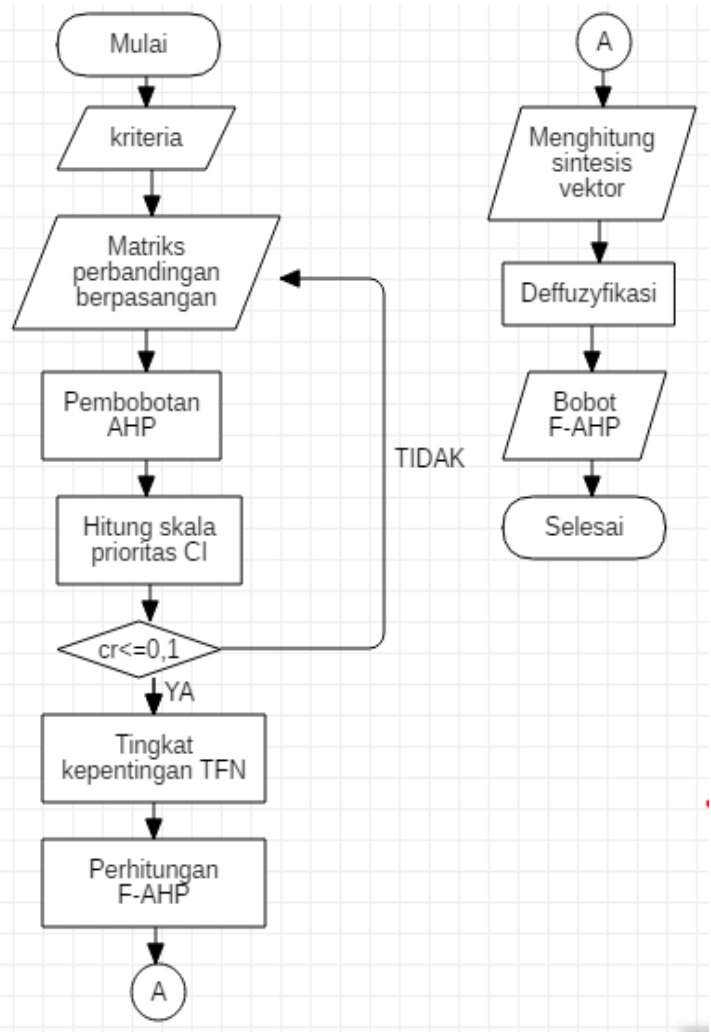

Gambar 5. Flowchart F-AHP

Pada gambar 5 Flowchart F-AHP menjelaskan tentang flowchart perhitungan F-AHP, mulai dari awal yaitu menentukan kriteria, matriks perbandingan berpasangan kemudian pembobotan dengan AHP, setelah itu akan dihitung nilai konsistensi CI dan akan menghitung nilai CR. Apabila nilai CR $<=0.1$ maka hasilnya konsisten, jika melebihi nilai tersebut maka tidak konsisten. Setelah itu masuk pada konversi tingkat kepentingan kriteria dengan skala TFN, Kemudian akan dilakukan perhitungan pembobotan dengan F-AHP sampai dengan menemukan bobot FAHP.

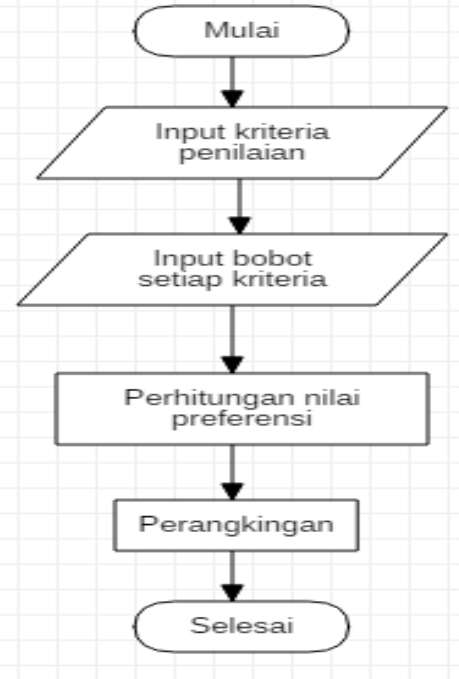

Gambar 6. Flowchart SAW

Pada gambar 6 flowchart $S A W$ menjelaskan tentang flowchart perhitungan SAW, mulai dari menginputkan nilai kriteria, menginputkan bobot setiap kriteria setelah itu melakukan perhitungan preferensi yaitu menjumlahkan hasil perkalian antara bobot kriteria dengan nilai kriteria yang terahir melakukan perangkingan

\section{ANALISA DAN PEMBAHASAN}

\subsection{Implementasi Sistem}

Paga Gambar 7 Halaman login merupakan halaman awal yang digunakan user agar bisa mengakses pada halaman selanjutnya. Halaman Login digunakan sebagai halaman hak akses yaitu halaman yang hanya digunakan oleh admin yang terdaftar pada database. Di halaman Login ini admin harus memasukkan username dan password yang sesuai, selanjutnya klik button login. berikut gambar halaman login.

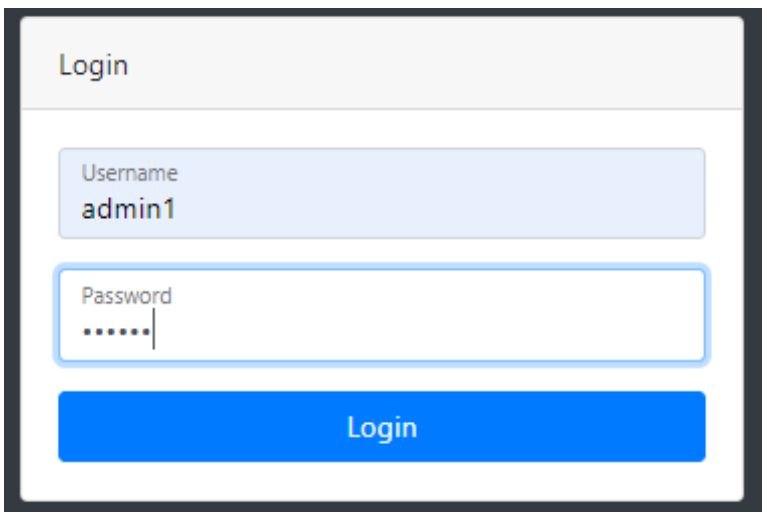

Gambar 7. Tampilan Login

Pada Gambar 8 Halaman menu utama merupakan halaman yang berisi menu-menu yang ada pada sistem 
pendukung keputusan calon penerima bantuan beras raskin.

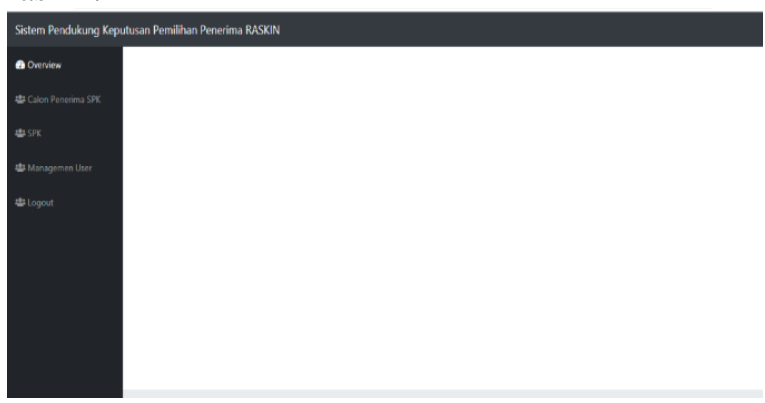

Gambar 8. Halaman Utama

Pada Gambar.9 Halaman calon penerima merupakan halaman yang berisi semua data calon penerima, disini kita bisa edit hapus dan menambah data calon penerima.

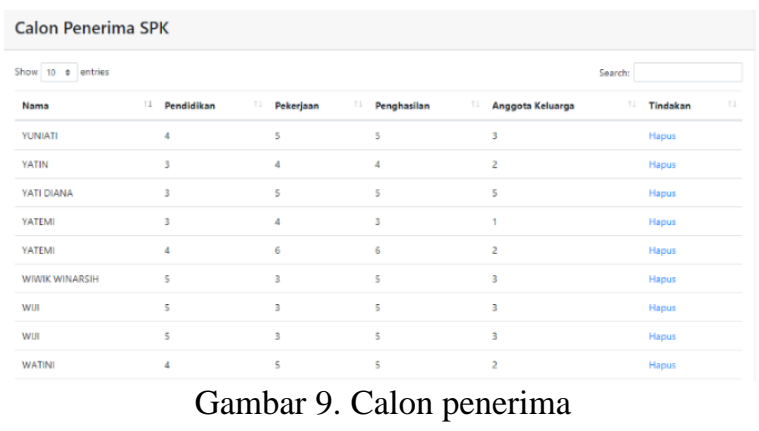

Pada Gambar.10 perangkingan admin dapat melihat hasil dari rangking Sistem Pendukung Keputusan Penerima RASKIN

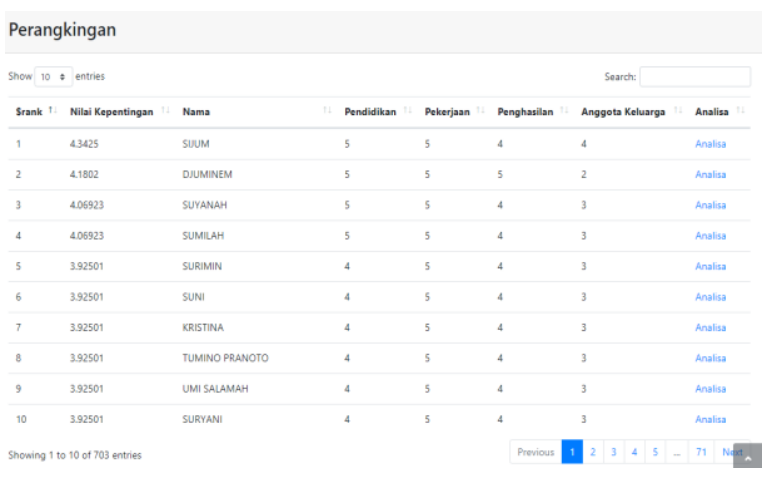

Gambar 10. Perengkingan Admin

\subsection{Pengujian}

Pengujian validasi digunakan untuk mengetahui apakah sistem yang dibangun sudah benar sesuai dengan yang dibutuhkan. Item-item yang telah dirumuskan dalam daftar kebutuhan fungsional menjadi acuan untuk melakukan pengujian validasi. Pengujian validasi menggunakan metode pengujian Black Box
Pada tahapan perhitungan nilai preferensi yaitu menjumlahkan hasil perkalian antara bobot kriteria dengan nilai kriteria. Berikut contoh perhitungannya:

$(2 * 0,14048)+(4 * 0,195928)+(4 * 0,39006)+(1 * 0,27353$

6) $=2,8984392$

$(3 * 0,14048)+(5 * 0,195928)+(1 * 0,39006)+(2 * 0,27353$

$6)=2,3382003$

$(5 * 0,14048)+(3 * 0,195928)+(4 * 0,39006)+(1 * 0,27353$

6) $=3,1239405$

$(3 * 0,14048)+(5 * 0,195928)+(4 * 0,39006)+(2 * 0,27353$

6) $=3,5083795$

$(3 * 0,14048)+(5 * 0,195928)+(1 * 0,39006)+(1 * 0,27353$

6) $=2,0646642$

$(4 * 0,14048)+(5 * 0,195928)+(4 * 0,39006)+(3 * 0,27353$

6) $=3,9223919$

$(4 * 0,14048)+(5 * 0,195928)+(3 * 0,39006)+(3 * 0,27353$

6) $=3,5323321$

$(4 * 0,14048)+(5 * 0,195928)+(4 * 0,39006)+(2 * 0,27353$

6) $=1,6728085$

$(5 * 0,14048)+(5 * 0,195928)+(4 * 0,39006)+(4 * 0,27353$

6) $=4.342556$

$(5 * 0,14048)+(5 * 0,195928)+(5 * 0,39006)+(2 * 0,27353$

$6)=4.180234$

$(5 * 0,14048)+(5 * 0,195928)+(4 * 0,39006)+(3 * 0,27353$

$6)=4.0692333$

$(4 * 0,14048)+(5 * 0,195928)+(5 * 0,39006)+(1 * 0,27353$

$6)=3,6488559$

$(3 * 0,14048)+(5 * 0,195928)+(1 * 0,39006)+(1 * 0,27353$

6) $=3,7653796$

$(4 * 0,14048)+(4 * 0,195928)+(3 * 0,39006)+(1 * 0,27353$

6) $=2,0646642$

$(5 * 0,14048)+(5 * 0,195928)+(4 * 0,39006)+(3 * 0,27353$

$6)=4.069236$

$(3 * 0,14048)+(5 * 0,195928)+(5 * 0,39006)+(1 * 0,27353$

6) $=3,6249032$

$(3 * 0,14048)+(3 * 0,195928)+(3 * 0,39006)+(1 * 0,27353$

6) $=2,452928$

Pada tahapan terahir melakukan perangkingan hasil dari nilai kriteria ini di kali kan bobot masingmasing kriteria, dimana perangkingan dilakukan berdasarkan perhitungan yang kemudian di urutkan dari hasil tertinggi hingga terendah. Berikut 3 besar hasil dari perhitungan perangkingan RASKIN diatas.

Tabel 1 Perangkingan

\begin{tabular}{|c|l|l|c|}
\hline No & \multicolumn{1}{|c|}{ Nama } & \multicolumn{1}{c|}{ Total nilai } & Rangking \\
\hline 10 & Sijum & 4.342556 & 1 \\
\hline 11 & Djuminem & 4.180234 & 2 \\
\hline 12 & Suyanah & 4.0692333 & 3 \\
\hline
\end{tabular}

\subsection{Analisa Hasil Pengujian}

Dari hasil pengujian dapat di analisis sebagai berikut

1) Semakin besar nilai bobot kriteria maka akan mempengaruhi besarnya nilai bobot global 
2) Yang mempengaruhi besar kecilnya perangkingan adalah nilai kriteria

3) Metode F-AHP dapat memberikan rekomendasi untuk penentuan RASKIN berdasarkan kriteria pendidikan, pekerjaan, penghasilan, dan anggota keluarga

4) Total bobot global yang paling besar merupakan warga yang paling layak mendapatkan bantuan besar RASKIN

\section{KESIMPULAN DAN SARAN}

Dari hasil implementasi dan uji coba aplikasi Sistem Pendukung Keputusan Menggunakan Metode F-AHP maka dapat dibuat kesimpulan sebagai berikut:

1) Metode F-AHP dapat memberikan rekomendasi untuk penentuan RASKIN berdasarkan kriteria pendidikan, pekerjaan, penghasilan, dan angggota keluarga

2) Hasil pengujian bahwa perancangan sistem telah menghasilkan sistem yang dapat membantu dalam pengambilan keputusan penentuan penerima Raskin secara otomatis dan objektif

Penelitian mengenai implementasi Metode Fuzzy Analytical Hierarchy Process pada sistem pendukung keputusan penerima raskin dapat dikembangkan dengan saran Menggunakan lebih banyak data fitur dan kriteria agar pertimbangan dalam proses perangkingan semakin akurat.

\section{DAFTAR PUSTAKA}

Gani, A. N., \& Assarudeen, S. M. (2012). A new operation on triangular fuzzy number for solving fuzzy linear programming problem. Applied Mathematical Sciences, 6(11), 525-532.

Kusrini, (2007), Konsep dan Aplikasi Sistem Pendukung Keputusan, Andi, Yogjakarta

McLeod Jr, R. (1998). Sistem Informasi Manajemen Edisi VIII. Jakarta: PT. Prenhallindo.

Rafifah, R. A. (2018). UPAYA HUMAS DALAM MENGHADAPI ISU NEGATIF PERUSAHAAN DI PERUM BULOG DIVISI REGIONAL JAWA TIMUR SURABAYA (Doctoral dissertation, Universitas Airlangga).

Turan, H. (2016). Weighing of Learning Factors Using Fuzzy Analytical Hierarchy Process. International Journal of Educational Sciences, 15(1-2), 134-141.

Turban, E., J. E. Aronson, dan T. Liang. (2005). Sistem Pendukung Keputusan dan Sistem Cerdas, Andi Offset, Jogyakarta 